\title{
Between the Old and the New Scheme: Management of New Chemical Substances in China
}

The existing regulatory framework for new chemical substances in China has been put in place for nearly a decade, delivering tangible results in advancing chemical management and promoting the well-regulated development of the chemical sector. In April this year, to address problems identified in its implementation, the Chinese authorities introduced a new scheme, known as MEE Order No. 12, which will take effect starting from 1 January 2021. With an enhanced focus on environmental risks, the new scheme is expected to enable more efficient and targeted regulation and contribute to the country's environmental protection efforts.

Nora Wang, Nadine He and Lancy Chen*

\section{Introduction}

China, similar to many other countries worldwide, regards chemical management as an important part in its domestic agendas and global actions, considering that the health and environmental hazards and workplace risks associated with chemicals have raised heightened concerns by both Government and the public. New chemical substances are particularly prioritized in China's chemical management initiatives, which is largely attributed to the uncertainties, potential risks and regulatory void as a result of their 'newness'.

The country's regulatory endeavours in this regard can be dated back to 2003, when the former State Bureau of Environmental Protection (SBEP) published the Measures on Environmental Management of New Chemical Substances (SBEP Order No. 17 of 2003), the first national-level regulation dedicated to new chemical management. The Measures laid out detailed regulations on the notification, registration and administration of new chemical substances, requiring that a pre-manufacture and pre-importation

\section{DOI: $10.21552 / \mathrm{icrl} / 2020 / 2 / 4$}

* Nora Wang is senior editor of the chemical portal of ChemLinked a regulatory information platform with REACH $24 \mathrm{H}<$ nora@chemlinked.com>. Nadine He is chief editor of the chemical portal of ChemLinked <nadine@chemlinked.com>. Lancy Chen is senior regulatory consultant of REACH24H <chenlan@reach24h.com> notification and registration system be put in place. It played a prominent role in reducing irregularities in the use of new chemical substances in China, curbing relevant risks and environmental pollutions and safeguarding public health.

However, SBEP Order No. 17 did not establish any integrated risk assessment system or risk prevention mechanism, and touched little on follow-up management after the completion of notification procedures, thus failing to effectively supervise the implementation of risk control measures.

In light of these problems as well as the burgeoning chemical industry that called for more profound regulatory changes, the former Ministry of Environmental Protection (MEP) revised the Measures and published it as MEP Order No. 7 in 2010. With its focus shifted from hazard assessment to risk assessment, the Measures optimized management approaches by putting equal emphasis on notification requirements and follow-up management practices, exercised classified measures, and therefore created a more scientific regulatory system for environmental management of new chemical substances.

MEP Order No. 7 has since then been in effect for a decade as an overarching framework for the country's new chemical management. However, since some of its provisions cannot address the immediate environmental management requirements, an overhaul had been discussed and worked on for years. In April this year, the Ministry of Ecology and Environ- 

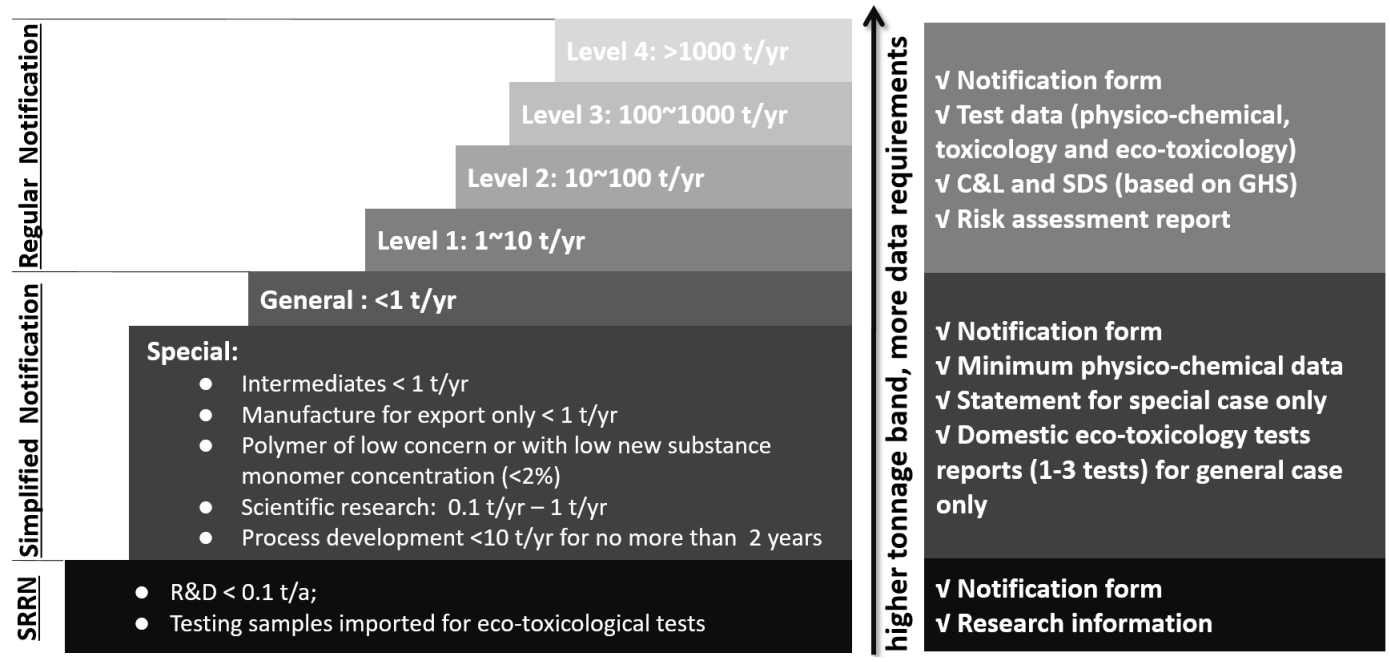

Figure 1: Notification types and data requirements under MEP Order No. 7

ment (MEE) published the amendments of MEP Order No. 7. The scheme is thereby renamed as the Measures for the Environmental Management Registration of New Chemical Substances (MEE Order No. 12 of 2020) and set to take effect starting from 1 January 2021.

This article will provide an overview of the existing regulatory framework for new chemical substances in China and the freshly unveiled MEE Order No. 12, and shed light on the industry implications of the new scheme.

\section{MEP Order No. 7}

On 19 January 2010, the former MEP issued the revised Measures for the Environmental Management of New Chemical Substances, namely MEP Order No.7. ${ }^{1}$ With improved philosophies, methodologies and strategies of chemical management, the revised Measures took effect on 15 October 2010.

It requires manufacturers and importers to complete notification of new chemical substances prior to manufacture or import. In the regulatory context of China, a new substance refers to any chemical substance that is not included in the Inventory of Existing Chemical Substances in China (IECSC). ${ }^{2} \mathrm{~A}$ foreign exporter may appoint a local Chinese agent (a similar role to 'Only Representative' under EU REACH) to submit new substance notifications. It also applies to new substances used as ingredients or intermedi- ates for pharmaceuticals, pesticides, cosmetics, food additives and feed additives, etc.

According to the purpose of manufacture/import and the quantities, notification of new chemical substances can be classified into three types, including: regular notification (four tonnage bands: $1-10 \mathrm{t} / \mathrm{yr}$, $10-100 \mathrm{t} / \mathrm{yr}, 100-1000 \mathrm{t} / \mathrm{yr}, 1,000+\mathrm{t} / \mathrm{yr}$ ), simplified notification (general case and special case) and scientific research record notification (SRRN). Minimum data requirements are provided for the different notification levels.

Notably, applicants for regular notification must submit a risk assessment report along with other application materials. MEP Order No. 7 is China's first regulation that requires submission of risk assessment reports in regards to chemical management, a reflection of the shift of its focus to risk management.

Under the current management system, new chemical substances subject to regular notification are of priority management. They are assessed and then categorized in three environmental management categories. In the last 9 years, $43 \%$ of the noti-

1 See, < http://www.gov.cn/gongbao/content/2010/content_1671246.htm> accessed 26 October 2020.

2 At present, the IECSC lists all existing chemical substances manufactured, processed, sold, used or imported inside mainland China between 1 January 1992 and 15 October 2003, and new chemical substances that were notified previously and five years have passed since they were first manufactured or imported. It now contains 45,947 substances (updated on 14 October 2020) in total. 


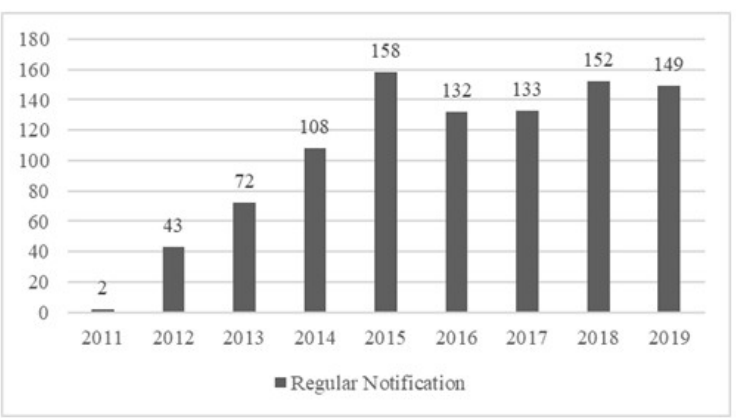

Figure 2: Regular notification from 2011 to 2019

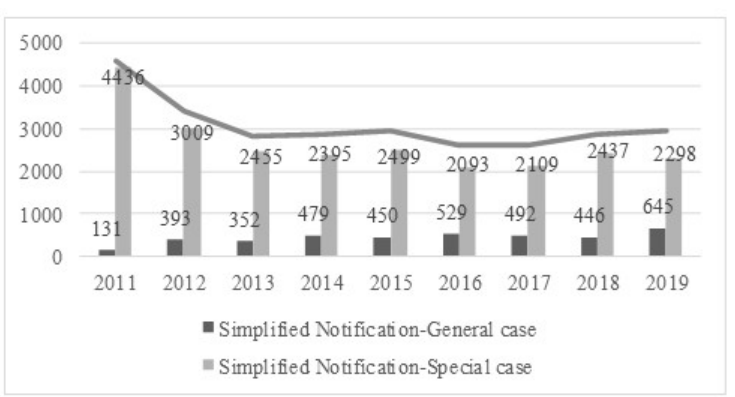

Figure 3: Simplified notification from 2011 to 2019



Figure 4: SRRN from 2011 to 2019

fied new substances fell under the category 'hazardous new chemical substances of priority environmental concern', 39\% as 'hazardous chemical substances' and $18 \%$ as 'general chemical substances'. Different post-notification obligations apply according to the categories, including information communication, reporting, and implementation of appropriate risk control measures indicated in the registration certificate, etc.

The charts below offer a graphical representation of the number of new chemical notification numbers approved in the last 9 years (from 2011 to 2019). The figures of SRRNs and simplified notifications are markedly higher than those of regular notifications. About $86 \%$ of simplified notifications are special cas- es, most of which are for polymers of low concern and polymers with low new substance monomer concentration $(<2 \% \mathrm{w} / \mathrm{w})$ that are largely exempt from regulation in foreign countries.

Post-notification requirements are specified in MEP Order No. 7 to exercise follow-up management. The holders of Regular Notification Certificates shall deliver relevant information to processors and users of their new chemical substances. For general chemical substances, certificate holders, processors and users shall implement risk control measures stated on the notification certificates. Differentiated reporting requirements are also provided for different certificate holders or substances, including first-time activity report, every-time activity report, five-year activity report and annual report.

In addition, to facilitate the implementation of MEP Order No. 7, a series of supporting documents, including national standards and technical specifications, were rolled out to provide guidance for enterprises on notification procedures, IECSC listing, chemical testing, hazard identification, risk assessment, etc.

With the revised Measures in effect, the past decade also witnessed great progress made in infrastructure development and regulatory capacity related to the environmental management of new chemical substances. So far, a total of 18 domestic testing institutes are capable of providing eco-toxicological testing data. Consulting companies have emerged nationwide to help foreign enterprises to comply with notification requirements. Authorities at both central and local levels have sharpened their regulatory awareness and capacity in the regulatory practices related to management of new chemical substances.

Nevertheless, some problems have become apparent during the implementation of MEP Order No. 7. The Measures is only a department-level legislation, thus delivering limited administrative effects. Statistics show that most of the approved applicants are foreign-based or foreign-funded enterprises; by contrast, many domestic enterprises are not fully aware of what they should do before manufacturing or importing any new chemical substance or, even worse, ignore their notification or registration obligations. Regulators have often bumbled in their efforts to determine if an enterprise manufactures or uses new chemicals but has not filed any notification application. Moreover, applications for low-risk substances have overwhelmingly outnumbered those for high- 
risk substances, thus taking up massive physical and human resources, which makes the focus on highrisk substances far from enough.

\section{MEE Order No. 12}

As an attempt to address the problems enumerated in the previous section and on the basis of international practices, domestic regulatory experiences and voices of industry players, the MEE published the amendment of the 2010 Measures, which is known as MEE Order No. 12, in late April this year. ${ }^{3}$ Set to take effect on 1 January 2021, the new Measures places a bigger focus on environmental risks, especially new chemical substances that are persistent and bioaccumulative, that are of great hazards to the environment and health or that may exist in the environment for a long time and may cause greater risks to the environment and human health. This underlying principle certainly echoes the draft Regulations on Environmental Risk Assessment and Control of Chemical Substances which was published in early 2019. ${ }^{4}$

It specifies that imported goods which are temporarily stored at the special customs supervision areas and designated for export to other countries without any processing will be excluded from its requirements. Exemptions are newly offered to fertilizers. On the other hand, it is made clear that for chemical substances which are included in the IECSC and subject to new usage environmental management ${ }^{5}$, where they are used for any industrial purpose other than the permitted ones, they will still be regulated as new chemical substances.

The most prominent change compared with MEP Order No. 7 lies in registration types, as shown in the table below.

Registration types have been significantly simplified: for substances which are subject to SRRN and simplified notification (except those for the PPORD purpose in quantities below 10 tons for no more than two years) under MEP Order No. 7, relevant businesses will need to apply for record notification after the new Measures takes effect; simplified registration and regular registration apply to substances in quantities of 1-10 tons per year or in quantities above 10 tons per year, respectively.

Optimized data requirements are provided for each type. For record notification, applicants only need to submit the known data concerning hazard properties and environmental risks information of new chemical substances. They can engage in relevant activities immediately after submitting all materials required for record notification. For simplified registration, applicants need to submit data concerning physicochemical properties, persistence, bioaccumulation and toxicity properties of new chemical substances. The data requirements for regular registration are no longer simply classified according to tonnage bands, but are instead considered based on hazards of new substances and exposure scenarios.

For highly hazardous chemical substances, applicants shall also submit socio-economic analysis materials, including an explanation on whether the new chemical substance in question has equivalent or evident advantages in performance or environmental friendliness, etc. compared with chemical substances which are already used in its application, so as to clarify the necessity of applying for its activity.

It should be noted that environmental risk assessment reports, still required for regular registration, will be a critical part in the review procedures. The MEE has recently published three draft technical guidelines ${ }^{6}$, which focus on environmental and health hazard assessment of chemical substance, environmental and health exposure assessment and environmental and health risk characterization, respectively, in a bid to provide guidance for enterprises and specify relevant technical requirements.

Follow-up management requirements are made more concrete and stringent in MEE Order No. 12. It emphasizes that enterprises assume primary responsibilities in follow-up management and commits to

3 See, $<$

https://www.mee.gov.cn/xxgk2018/xxgk/xxgk02/202005/t202005 07_777913.html> accessed 26 October 2020

4 See, <

https://www.mee.gov.cn/xxgk2018/xxgk/xxgk06/201901/t201901 11_689258.html> accessed 26 October 2020. The Regulations, once officially published, will be a significant landmark in legislating China's chemical management, as it, for the first time, incorporates all chemical substances manufactured, processed or imported in China into a unified environmental risk assessment and control mechanism of chemical substances.

5 According to MEE Order No. 12, where (1) highly hazardous chemical substances; and (2) chemical substances that are persistent and bioaccumulative, or persistent and toxic, or bioaccumulative and toxic are listed into the IECSC, they shall be subject to new usage environmental management.

6 See,

<https://www.mee.gov.cn/xxgk2018/xxgk/xxgk06/202009/t20200 930_801876.html> accessed 26 October 2020. 
Table 1: Differences between MEP Order No.7 and MEE Order No. 12 on registration types

\begin{tabular}{|c|c|c|}
\hline Substance type & MEP Order No.7 & MEE Order No. 12 \\
\hline $\begin{array}{l}\text { Substances for R\&D purpose, in quanti- } \\
\text { ties below } 0.1 \mathrm{t} / \mathrm{yr}\end{array}$ & SRRN & $\begin{array}{l}\text { No longer a separate registration type; } \\
\text { subject to record notification }\end{array}$ \\
\hline $\begin{array}{l}\text { Substances manufactured/imported in } \\
\text { quantities below } 1 \mathrm{t} / \mathrm{yr}\end{array}$ & Simplified notification (general case) & Record notification \\
\hline $\begin{array}{l}\text { 1. Intermediates manufactured/import- } \\
\text { ed below } 1 \mathrm{t} / \mathrm{yr} \\
\text { 2. Substances manufactured for the } \\
\text { sole purpose of export, in quantities } \\
\text { below } 1 \mathrm{t} / \mathrm{yr} \\
\text { 3. Substances for R\&D purpose, in } \\
\text { quantities of } 0.1-1 \mathrm{t} / \mathrm{yr} \\
\text { 4. PLC, or a polymer with low new } \\
\text { chemical substance concentration of } \\
\text { monomer }<2 \%(\mathrm{w} / \mathrm{w})\end{array}$ & Simplified notification (special case) & Record notification \\
\hline $\begin{array}{l}\text { Substances for the purpose of Product } \\
\text { and Process Orientated Research and } \\
\text { Development (PPORD), in quantities } \\
\text { below } 10 \text { tons for no more than two } \\
\text { years }\end{array}$ & Simplified notification (special case) & Simplified registration \\
\hline $\begin{array}{l}\text { Substances manufactured/imported in } \\
\text { quantities of } 1-10 \mathrm{t} / \mathrm{yr}\end{array}$ & Regular notification (Level ı) & Simplified registration \\
\hline $\begin{array}{l}\text { Substances manufactured/imported in } \\
\text { quantities above } 10 \mathrm{t} / \mathrm{yr}\end{array}$ & Regular notification (Level 2, 3 and 4) & Regular registration \\
\hline
\end{tabular}

practice more targeted environmental risk control measures, and optimizes regulatory approaches and priorities and reporting requirements. These improvements are expected to enable sound management throughout the lifecycle of chemicals.

In cases where record notifications are required, since applicants can carry out activities related to new chemicals immediately after they submit relevant materials, random checks of compliance are an important way to ensure follow-up management in this regard. Moreover, checking the compliance of record notifications of polymers will be a key focus in the follow-up management work. MEE Order No.12 provides that, record notifications are required for polymers containing less than $2 \%$ monomers or reactants which are new chemical substances, or polymers of low concern, regardless of their annual volumes.

MEE Order No. 12 lifts the requirements for submission of every-time activity report and five-year activity report, requires businesses to submit only an annual report and a first-time activity report. Under the new scheme, however, the first-time activity report is required for both simplified registration and regular registration applicants, and the annual report is only required for substances for which the submission of an annual report is specified as an environmental management requirement in the Regular Registration Certificate.

As for listing registered new substances into the IECSC, only those that have finished regular registration are qualified to be listed into the IECSC by the MEE after 5 years from the date of registration. New substances that are highly hazardous, or persistent and bioaccumulative, or persistent and toxic, or bioaccumulative and toxic should be assigned permitted purposes upon their addition into the IECSC. For new highly hazardous substances, or new substances which are persistent and bioaccumulative, or persistent and toxic, or bioaccumulative and toxic, corresponding environmental management require- 
ments shall be stipulated in addition to annul reporting requirements upon their addition into the IECSC.

\section{Conclusions}

Overall, compared with its predecessors, MEE Order No. 12 provides a more solid institutional framework for the environmental management of new chemical substances in China by placing a larger focus on substances with relatively high risks, thus representing another step forward towards its equivalents in other countries, such as REACH in EU.

With simplified registration types and optimized data requirements, the new scheme will remarkably ease the burdens on enterprises and encourage them to gradually phase out high-risk chemical substances and turn to environmentally friendly ones. This makes the new scheme a profound move to boost China's environmental protection efforts.

However, that does not mean enterprises can take it lightly: the stronger oversight exercised both dur- ing and after the handling of matters will press enterprises to devote more efforts to ensure regulatory compliance. Enterprises are required to assume primary responsibilities in environmental risk control of new chemical substances, implement environmental management requirements, and accept the supervision and spot checks of authorities.

To provide further instructions on how to apply for registration and notification of new chemical substances under MEE Order No. 12 and elaborate on requirements which are not sufficiently detailed in the Measures, the MEE published the draft Guidance on Environmental Management Registration of New Chemical Substances ${ }^{7}$ to solicit public comments. An official version is expected to come out soon. Businesses will need to keep a close eye on regulatory updates and comply with them based on thorough understanding.

7 See,

<http://www.mee.gov.cn/xxgk2018/xxgk/xxgk06/202008/t202008 17_793827.html> accessed 26 October 2020. 